\title{
‘REALIDADES': O BRASIL QUE SE CONSTRÓI SOB O OLHAR DA VENEZUELA, TELESUR TV
}

\author{
Antônio M. Elíbio Júnior \\ UNISUL \\ tonyelibio@unisul.br \\ Beatrice C. O. Gonçalves \\ Jornalista - UNISUL
}

Resumo: Este artigo propõe discutir a participação brasileira dentro da programação da Televisión Del Sur, TeleSUR Tv, tendo como objeto de estudo o programa "Realidades", definido pela emissora como um espaço semanal que mostra e detalha a América Latina. Para esta pesquisa foram analisadas seis reportagens referentes ao Brasil que abordaram, no período de agosto a novembro de 2006, a participação econômica, política e social do país na América Latina.

Palavras-chave: América Latina; televisão; integração; Brasil.

\section{'Realities': The Brazil that it's made under the Venezuela's watch, TeleSur TV}

\begin{abstract}
This article intends to discuss the brazilian participation in the Television Del SUR, TeleSUR TV. It's having as subject of the study the tv show "Realidades", defined by the channel TeleSUR as a weekly space that shows and details Latin America. For this research it was necessary to analise six reports about Brazil that talked about the economic, social e political participation of the country in the construct of Latin America during august to november, 2006.
\end{abstract}

Key words: Latin America; television integration; Brazil.

\section{Introdução}

“Vernos es conocermos, reconocermos es respetarnos, respetarnos es aprender a querernos, querernos es el primer paso para integrarmos"1. Com esse lema, surge em 24 de julho de 2005, data em que se celebravam os 222 anos do nascimento de Simon Bolívar, a TeleSUR Tv.

Com sede em Caracas, o canal tem caráter de empresa multiestatal e tem como sócios Argentina, Bolívia, Cuba, Uruguai e Venezuela. O Brasil não é associado à emissora, só participa como membro colaborador da programação. 
Através de acordo com a direção da TeleSUR, o país dá apoio logístico aos correspondentes do canal em Brasília. A não participação efetiva foi uma opção do governo brasileiro, que resolveu investir em seu próprio meio "integracionista", o canal Brasil Integrácion. Mesmo assim, o país está no ar e na tela da TeleSUR. Todos os dias, uma equipe permanente de seis correspondentes faz uma matéria referente ao Brasil para ser transmitida na programação jornalística da TeleSUR.

Este artigo propõe discutir a participação brasileira dentro da programação do canal, tendo como objeto de estudo o programa "Realidades", definido pela emissora como um espaço semanal que mostra e detalha a América Latina ${ }^{2}$. Dentro desse contexto, foi preciso discutir o que a televisão significa para a América Latina, o que coloca em pauta e como aborda as questões sociais além de analisar os recentes acordos firmados entre Venezuela, Cuba e Bolívia para a formação da Aliança Bolivariana das Américas (Alba), a entrada da Venezuela no Mercosul, bem como a maior participação desses países nos acordos políticos, econômicos e culturais da Latino América ${ }^{3}$.

\section{TV na América Latina}

Os Estados Unidos é uma característica do moderno imperialismo com caráter de financeiro que não desejam tomar os territórios da América Latina e exterminar toda a propriedade das classes dominantes, senão alugá-las ao seu serviço e até melhorá-las como tal, para que lhes proporcionem a exploração do que eles necessitem. ${ }^{4}$

Mais de 500 milhões de latino-americanos acompanham diariamente os programas de tv. São novelas, seriados, documentários e programas jornalísticos que começaram a fazer parte da rotina do subcontinente na década de 50 e 60 . A chegada e a consolidação da tv nos mais de 33 países da América Latina se dá principalmente por iniciativa estatal, mas financiada pelo capital privado de empresários da região e por empresas norte-americanas.

Em todos esses países, o sistema de atribuição de canais fundamenta-se em ato administrativo, cabendo aos governos autorizar, conceder ou permitir o uso das ondas hertzianas. Dessa forma, o Estado, ao estimular e investir na televisão, autoriza seus cidadãos a pensar e a se reconhecer de uma outra forma e o meio televisivo passa a ser a mensagem da intervenção social ${ }^{5}$.

Entre os países pesquisados neste trabalho, Brasil ${ }^{6}$, Argentina $^{7}$, Bolívia $^{8}$ e Venezuela ${ }^{9}$, cada um a seu modo, viu a televisão se consolidar como o mais influente meio de comunicação através do maciço investimento de empresas privadas, como a norte-americana Time-Life ${ }^{10}$. Esses investidores ajudaram a baratear os custos da programação televisiva e a estimular seu consumo. 
Segundo estimativas da Unesco, uma emissora de tv para transmitir 100 horas semanais, necessitaria de um orçamento variável de 16 a 52 milhões de dólares anuais para produção. Seguindo isso, se a maioria das tvs da América Latina não importassem programas de baixo custo, elas seriam economicamente inviáveis. ${ }^{11}$

Com o objetivo de recrear e entreter, os investidores internacionais passam a exportar o modelo e o formato dos programas já veiculados na grade televisiva de países como o EUA, para as mais diferentes populações latino-americanas. Era o momento de impor princípios de visão de mundo que pudessem universalizar particularismos, em uma relação de comunicação coercitiva.

O imperialismo cultural é uma violência simbólica, que se apóia numa relação de comunicação coercitiva para extorquir a submissão e cuja particularidade consiste, neste caso, no fato de universalizar particularismos vinculados a uma experiência histórica singular, ao fazer com que sejam desconhecidos, como tal, e reconhecidos como universais. ${ }^{12}$

A televisão latino-americana nasce e se desenvolve como um instrumento de comunicação muito pouco autônomo, sobre o qual pesa toda uma série de restrições. "Não há lugar para a improvisação, para a palavra livre, desenfreada, arriscada demais ou mesmo perigosa" ${ }^{13}$. Fundamentada em relações de mercado, de livre concorrência, em limitações de tempo e nos critérios de objetividade, a tv ajuda a construir bens culturais que não fogem às regras da manutenção da ordem simbólica existente.

A televisão passa a conferir autoridade e a construir uma realidade capaz de exercer efeitos sociais de mobilização ou desmobilização no momento em que faz o to record dos fatos. É nesse novo ambiente social complexo, de livre comunicação de idéias e valores é, talvez, o principal dos múltiplos desafios da modernidade. ${ }^{14}$

É preciso mostrar, assim, um contexto social onde tudo funciona bem, onde todos desempenham o seu papel, onde a lei, a ordem econômica e os agentes sociais estão todos em harmonia. Em que se estimule o pensar, mas desde que seja por idéias feitas. Em uma troca de lugares-comuns, em que a comunicação não tem outro conteúdo a não ser o fato mesmo da comunicação. ${ }^{15}$

A televisão é um universo em que se tem a impressão de que os agentes sociais, tendo as aparências da importância, da liberdade, da autonomia, e mesmo por vezes uma aura extraordinária, são marionetes de uma necessidade que é preciso descrever, de uma estrutura que é preciso tornar manifesta e trazer à luz. ${ }^{16}$ 


\subsection{Construção dos Impérios Midiáticos Latino - Americanos}

Os acordos financeiros entre investidores internacionais e empresários da comunicação latino-americanos não se resumiram apenas à troca de experiências e a venda de produtos e formatos das redes dos EUA aos países sul e centro americanos. A principal cadeia televisiva brasileira, a rede Globo, foi montada com US\$ 6 milhões de dólares, dinheiro conseguido através de empréstimos feitos pelo dono do canal, Roberto Marinho, junto à empresa norte-americana Time-Life em $1966^{17}$.

Com o dinheiro, Roberto Marinho expandiu seus investimentos. Além da emissora do Rio de janeiro, comprou a Tv Paulista que funcionou como uma espécie de afiliada da Globo. Já na década de 70, na fase mais repressiva da ditadura militar (1964 - 1985) a Globo consolidou sua liderança como a rede de televisão mais assistida no Brasil com índices de audiência de 70 a 80 pontos $^{18}$.

Estreitando seus vínculos com a ditadura, a emissora buscou ignorar ou desqualificar quaisquer manifestações de descontentamento com o regime. Assim, em 1975, veiculou a versão oficial, de suicídio, acerca da morte do jornalista Vladimir Herzog nas celas da polícia política de São Paulo. ${ }^{19}$

Hoje o grupo que tem sob controle o sistema Globo possui cinco estações de TV e 108 afiliadas de TV aberta, os sistemas por assinatura Net e Sky Multi Country, a Globopar, Globosat, as editoras Globo, portal de internet, a Globofilmes e Gravadoras e os Sistema Globo de rádio, além de ser acionista dos jornais O Globo, Extra, Diário de São Paulo e Valor Econômico.

O caso brasileiro não é o único na América Latina. A tv venezuelana também se fortalece a partir da década de 60 com investimentos internacionais. Em parceria com a rede norte-americana $\mathrm{ABC}$ e com a empresa Monsanto, o grupo venezuelano Cisneros montam o canal Venevisión em 1961.

Era o começo de um império midiático que hoje faz do grupo Cisneros a segunda maior fortuna da América Latina, com um patrimônio superior a US\$ 5 bilhões. O grupo tem como presidente Gustavo Cisneros, o grande magnata das comunicações na Venezuela, que é proprietário ou sócio de cerca de 70 empresas estabelecidas em 40 países, empregando aproximadamente 37 mil pessoas.

Gustavo Cisneros sempre foi um homem muito próximo do poder em seu país. Essa característica foi interrompida após a eleição de Hugo Chávez para a presidência da Venezuela em 1998. Tanto é que a Venevisión tornou-se um dos principais pólos de oposição ao governo e esteve diretamente relacionada ao golpe de Estado de 11 de abril de 2002.

Gustavo Cisneros estava na Venevisión [...] . O canal [...] era um lugar para onde os dirigentes políticos, empresariais, 
sindicais e intelectuais iam em tempos de crise [...]. Ali estava o líder sindical Carlos Ortega [...] Também estava lá o presidente da Fedecámaras ${ }^{20}$, Pedro Carmona. ${ }^{21}$

\subsection{Caso venezuelano - o Golpe Midiático}

Membro do Movimento Bolivariano Revolucionário 200 (MBR-200), o tenente-coronel Hugo Chávez participou das eleições venezuelanas em 1998. Seu discurso nacionalista conquistou mais de 3,67 milhões de votos, que o elegeram presidente da Venezuela com $56,2 \%$ dos sufrágios válidos.

A vitória chavista representou a chegada da nova esquerda venezuelana ao poder. Resultado da alta popularidade do Movimento Bolivariano Revolucionário que desmoralizou os detentores do poder no país com a tentativa de golpe de Estado em 1992.22 Quando assumiu a presidência em 1998, Chávez provocou mudanças estruturais na Venezuela. Promoveu a eleição de constituintes para os cargos executivos, legislativos federal, estadual e municipal, estendendo o mandato presidencial (com possibilidade de reeleição) e alterou o nome do país que passa a ser chamado de República Bolivariana da Venezuela.

Os populismos colocaram a elaboração da política de massas num plano endógeno, recuperando assim, uma memória histórica coletiva capaz de fundir como mito, demandas de classe, demandas de nação e de demandas de cidadania, num único movimento que reclama a herança paternalista e caudilhista da concepção tradicional de política. ${ }^{23}$

Um discurso que promoveu três grandes ataques ${ }^{24}$ das antigas oligarquias venezuelanas e da própria mídia local contra o governo de Chávez. Durante os primeiros meses de 2002, as tvs privadas venezuelanas questionavam seus telespectadores: "Você acha que o presidente está louco?"25. Entre 11 e 13 de abril daquele mesmo ano, as redes de tv do país, em especial a Venevisión, chamavam a população para uma grande marcha à sede da $\operatorname{PDVSA}^{26}$ que culminaria na retirada de Chávez do poder. No embate entre pró - Chávez e opositores do governo, o presidente decide deixar o cargo, mas sem assinar renúncia para evitar um bombardeio ao palácio Miraflores. Esses mesmos canais privados de tv que durante os dias do conflito optaram em transmitir seriados norte-americanos a expor o golpe, passam a mostrar, após a saída de Chávez da presidência, depoimentos dos golpistas. Ao vivo e em cadeia nacional, eles revelaram todo o plano em detalhes e agradeceram as emissoras RCTV, Televen, CMT e Globovísion pelo apoio manifestado.

O documentário A Revolução Não Será Televisionada (produzido por Kim Bartley e Donnacha O'Brian durante os dias 11 e 13 de abril de 2002) mostra a 
entrevista coletiva de Pedro Carmona após o golpe. "Foi decidido que as Forças Armadas mantenham sob custódia o presidente que está saindo, o presidente Chávez, e que se forme imediatamente um governo de transição". O governo norteamericano também se manifestou sobre o golpe. O então Secretário de Estado dos Estados Unidos, Colin Powell, afirmou em depoimento na Casa Branca que: "Estamos preocupados com algumas ações do presidente Chávez e a sua noção de sistema democrático".

Chávez ainda preso no palácio conseguiu reunir o povo nas ruas e a sua guarda nacional para dar início a um contra-golpe. Pediu que a população voltasse às suas casas e que a oposição respeitasse a Constituição e o seu mandato, já que ele havia sido eleito pela maioria e de forma democrática. Chávez volta ao poder após 28 horas de golpe. Mas os ataques ao seu governo não pararam por aí. A oposição reuniu mais de $20 \%$ de assinaturas dos eleitores aptos a votar e convocou, para 15 de agosto de 2004, um referendo que questionava a permanência ou não de Chávez no poder. Mais uma vez, o presidente venceu a disputa com 58,9\% dos votos a favor da continuação de seu mandato. Em pouco mais de seis anos de governo, Chávez enfrentou três grandes golpes. Para que pudesse continuar seu mandato até o fim, o presidente venezuelano vê a necessidade de se construir uma nova rede de apoios. Dentro dessa estratégia política, estaria a de fortalecimento do poder estatal nos meios de comunicação. Chávez cria o programa Alô Presidente (pronunciamento presidencial que é veiculado em mais de 100 emissoras de tv e rádio de seu país ${ }^{27}$ ) além de propor a criação de um novo meio televisivo: a TeleSUR Tv. Com objetivos, missões e conceitos claros, os novos aparatos de comunicação procuram consolidar a liderança chavista tanto em seu próprio país quanto em toda América Latina.

\subsection{Se o propósito é a integração, a TeleSUR é o meio}

Montesquieu assinalou que os costumes de um povo não se mudam por meio de leis, mas por outros costumes e exemplos, ou seja, pela educação popular. E por aí se vê a essencial ligação entre democracia moderna e a comunicação televisiva. Se o correto funcionamento das instituições democráticas supõe a existência de costumes populares democráticos; se a televisão é o grande poder social que forja a mentalidade e os costumes do povo, a democratização da tv deveria ser a primeira e principal tarefa de um programa de instauração democrática. ${ }^{28}$

A TeleSUR Tv nasce em 24 de julho de 2005, no mesmo dia em que se celebravam os 222 anos do nascimento de Simon Bolívar. Era o início do projeto da multiestatal com sede em Caracas que se propõe a ser a alternativa audiovisual que 
trabalha para o fomento da identidade latino-americana mediante uma programação televisiva, além de ter como compromisso a integração da América Latina ${ }^{29}$.

Frente al discurso único sostenido por las grandes corporaciones, que deliberadamente niegan, coartan oignoran el derecho a la información, se hace imprescindible una alternativa capaz de representar los principios fundamentales de un auténtico medio de comunicación: veracidad, justicia, respeto y solidaridad. ${ }^{30}$

Segundo o site da TeleSUR TV, o canal tem como sócios-fundadores a Argentina (com 19\% das ações), Bolívia (6\%), Cuba (19\%), Uruguai (5\%) e Venezuela (51\%). Além de contar com o apoio de uma rede de membros colaboradores, entre eles o Brasil.

Com a Telesur nós vamos recobrar as palavras. Não é só uma ferramenta, é uma retomada da voz que nos tinha sido seqüestrada durante 33 anos de ditadura. Nós temos que fugir do estereótipo que colocaram sobre nós. A TeleSUR é o lançamento de uma fábrica latino-americana de idéias ${ }^{31}$.

Respaldada na Constituição venezuelana de 1999, a TeleSUR fundamenta seus objetivos, metas e missões em um trabalho de expressão livre de comunicação, o que segundo o site do canal, é um dos elementos cruciais da democracia participativa. Além disso, se posiciona como um meio de notícias tão diversas e plurais, quanto diversas e plurais são as populações latino-americanas.

Em suas 24 horas de programação, dividida entre noticiários, revista semanal, análises jornalísticas, entrevistas e reportagens, o canal procura dar visibilidade às lutas sociais, aos conhecimentos populares e aos movimentos de identidade latino-americana. Para a produção de vídeos e reportagens a emissora mantém uma rede de correspondentes permanentes em Bogotá, Brasília, Buenos Aires, Caracas, Cidade do México, Havana, Porto Príncipe, La Paz, Washington e uma rede de colaboradores em toda região de cobertura.

TeleSUR, la nueva televisión del Sur, nace de una evidente necesidad latinoamericana: contar con un medio que permita, a todos los habitantes de esta vasta región, difundir sus propios valores, divulgar su propia imagen, debatir sus propias ideas $y$ transmitir sus propios contenidos, libre y equitativamente. ${ }^{32}$

A TeleSUR é transmitida via satélite desde Caracas através de um sinal aberto, estando disponível para a América do Sul, Centro América, América do Norte, Caribe, Europa Ocidental e Noroeste da África. Em seu site www.telesurtv. net, o canal ainda disponibiliza sua programação ao vivo, a rádio web da emissora e textos referentes à história e ao contexto da América Latina. 
A chegada da TeleSUR no Brasil se deu através de parcerias da multiestatal com emissoras educativas e comunitárias do país. O primeiro canal a retransmitir parte da programação em sua grade foi a TV Educativa do Paraná. Já o canal comunitário Tv Floripa (da rede de Tv a cabo Net Florianópolis, canal 4) é o que disponibiliza maior tempo em sua programação para a retransmissão da TeleSUR $\mathrm{Tv}^{33} \mathrm{O}$ governo brasileiro foi convidado para ser sócio do canal, mas preferiu investir em seu próprio meio "integracionista”, o canal Brasil Integración. Como membro colaborador, o país dá apoio logístico a equipe de seis funcionários brasileiros da TeleSUR (chefe- de- redação, produtor, repórter, dois câmeras e diretor administrador) pagos pelo governo da Venezuela.

Encaramos com otimismo as atividades da TeleSUR, porque vemos nascer na América do Sul, um espaço público internacional, que começa a gerar seus próprios veículos de comunicação. ${ }^{34}$

\subsection{Construção do Brasil da TeleSUR}

Como sucursal permanente da TeleSUR, os correspondentes de Brasília são obrigados a produzir diariamente uma matéria para a programação de noticiários do canal que vão ao ar no período da manhã, meio-dia e da noite. As reportagens têm em média dois minutos e precisam trabalhar com os conceitos de justiça, veracidade e identidade do povo latino.

Para que as matérias das sucursais estejam de acordo com os princípios do canal, toda quinta-feira é enviada à sede administrativa da TeleSUR em Caracas uma previsão de pautas para a semana posterior. Nas sextas-feiras há uma reunião na Venezuela que avalia as sugestões de reportagens e faz a seleção daquilo que vai ao ar. Só com o aval da direção do canal é que os correspondentes saem a campo para coletar as informações, sonoras e imagens. Com o material em mãos, os jornalistas escrevem os textos das reportagens e encaminham para a equipe em Caracas, que o revisa, se assim precisar, e autoriza a gravação do material ${ }^{35}$. A matéria é então editada e enviada pela internet a Caracas. Ao chegar à Venezuela a reportagem é dublada para o espanhol e, caso ainda precise de revisões, é reeditada. Desse modo, a sede da TeleSUR Tv consegue controlar e dirigir tudo o que vai ao ar no canal. Não há frases, imagens e sonoras que não tenham sido pensadas e repensadas antes de serem exibidas. Para o diretor-executivo do canal no Brasil, Beto Almeida, a multiestatal chega para fazer um jornalismo não-panfletário, mas que ao mesmo tempo não é imparcial.

Na construção diária do Brasil que passa na TeleSUR Tv, o editor-chefe do canal no país ${ }^{36}$, Alexandre Ribondi, conta que é preciso mostrar as demais regiões da América Latina uma realidade que, em muitas vezes, é desconhecida. 
"Precisamos mostrar o que é ser um brasileiro, o que ele come, o que vê, o que faz". Como a sucursal permanente brasileira fica em Brasília, não há como não notar nas reportagens produzidas o olhar de profissionais que vivem no Distrito Federal. As matérias costumam ter fontes oficiais, como embaixadores ou membros do governo federal. O que, segundo o editor-chefe da sucursal Alexandre Ribondi, é visto com receio pela sede do canal. A sucursal ainda enfrenta o problema de produzir matérias com movimentos sociais e organizações não governamentais que não tenham unidades em Brasília.

Falar sobre o trabalho da TeleSUR Tv no Brasil é ainda discutir o mandato de Luiz Inácio Lula da Silva e seus projetos tanto para o Brasil quanto para a América Latina, já que foi no governo de Lula que a multiestatal se formou. Tanto para a TeleSUR quanto para o governo venezuelano, o Brasil de Lula foi o que disse não ao convite para se tornar sócio- fundador do canal, que preferiu investir em seu próprio meio televisivo de integração do subcontinente e um país que opta pelo pagamento da dívida externa junto ao Fundo Monetário Internacional (FMI) ${ }^{37}$.

\section{O Brasil da TELESUR TV}

De 17 de agosto a 02 de novembro de 2006, o Brasil foi para o programa "Realidades" 38 da TeleSUR Tv o país dos trabalhadores que administram uma indústria de plásticos, um grupo de pesquisadores que lança livro sobre a América Latina, um lugar que vê diminuir a taxa de desemprego, que acompanha a participação da mulher no mercado de trabalho mundial e no cenário político brasileiro. Ao longo dos 10 programas ${ }^{39}$ "Realidades" transmitidos, o país virou notícia em quatro edições transmitidas às quintas-feiras às $11 \mathrm{~h} 30$, nos dias $17 \mathrm{de}$ agosto, 5 e 19 de outubro e em 2 de novembro. Com uma média de oito matérias por programa, o "Realidades" dá espaço para o detalhamento de notícias que, muitas vezes, já foram pautadas nos noticiários do canal, mas que são temas que poderiam ser aprofundados em matérias de até cinco minutos.

Dividido em três blocos, o programa tem ainda certas peculiaridades que o diferem da programação habitual da TeleSUR. A apresentadora e responsável pelo programa, Libertad Velascos, reforça a cada edição as missões do canal como as necessidades de conhecer a América Latina, de entender seus contextos e de ver o mundo desde o sul.

Una señal de vocación social, que se constituya a un tiempo en memoria histórica y expresión cultural; un canal de encuentro y debate de ideas, compuesto por una programación tan diversa y plural como diversa y plural es la población latinoamericana. ${ }^{40}$

Os primeiros blocos do programa são destinados a matérias que envolvem 
problemas enfrentados pelo continente, como a falta de médicos nas regiões tomadas por conflitos armados na Colômbia, trabalho infantil e moradias irregulares nos Andes peruanos. O segundo bloco de "Realidades" costuma ser apresentado por Libertad como aquele destinado a realidades construtivas ou positivas e que tragam soluções para a América Latina. A terceira e última parte do programa costuma apresentar questões culturais, como pratos típicos e a arte local de cada país.

\section{1- Ocupação da indústria de plásticos Cipla:}

"A boa notícia é que os bancos dizem que a empresa de plásticos Cipla é rentável e viável. Mas vamos deixar que os próprios trabalhadores contem como eles tornaram isso possível." ${ }^{41}$ Foi assim que Libertad Velascos apresentou a matéria sobre a administração operária da fábrica de plásticos Cipla em 17 de agosto. A vídeo- reportagem fez parte de uma série produzida sobre a ocupação de fábricas por trabalhadores.

A reportagem brasileira foi produzida pela equipe da Tv Educativa do Paraná, um dos canais colaboradores da TeleSUR no Brasil. Diferente da equipe de correspondentes brasileiros funcionários da Venezuela que trabalham na sucursal de Brasília, o grupo de jornalistas paranaenses não têm a obrigatoriedade de enviar matérias à sede do canal na Venezuela. Desse modo, só são produzidas reportagens que tenham sido "encomendadas" pela sucursal brasileira ou aquelas que sejam oferecidas ao canal pelos colaboradores. A reportagem, com cerca de três minutos, começa com a imagem de uma placa: Empresa sob o controle dos operários. $\mathrm{O}$ texto explica que hoje os trabalhadores têm o controle administrativo, financeiro e operacional da indústria. Quanto ao patrão que devia salários, que não pagava os impostos ao governo estadual e federal há mais de dez anos e que levou a fábrica a falência, ele não existe mais. "Agora todos trabalham juntos, todos participam das reuniões, agora existe comunicação. Antes a fábrica ia quebrar e eu nem sabia", afirmaram os funcionários da Cipla, Paulo Drecht e Paulino Joaquim, em entrevista a reportagem da Tv Educativa do Paraná. Em seguida, a repórter Karen Hirami, faz uma passagem no vídeo dizendo que os funcionários não acabaram com as hierarquias, ainda existe a figura do chefe e do diretor, mas acima deles há uma comissão de 29 trabalhadores eleitos pela maioria, que decidem os rumos da fábrica em assembléias.

Mesmo com as dificuldades em pagar os mais de 60 milhões de reais contraídos em dívidas pelo antigo proprietário, a Cipla conseguiu aumentar em $50 \%$ sua produtividade. Através de um acordo com o governo de Hugo Chávez, a Venezuela envia matéria-prima para a fabricação de canos e, em troca, a empresa envia à Venezuela os materiais produzidos que serão utilizados na construção de casas populares. A matéria termina fazendo exigências ao governo federal 
brasileiro. A solução apresentada para que a empresa se torne ainda mais lucrativa é a estatização. "Os funcionários da Cipla esperam que o governo tome a empresa e a transforme em uma estatal", finaliza a repórter Karen Hirami. Essa exigência dos trabalhadores e, nesse caso também, do programa "Realidades", tem origem nos ideais marxistas ${ }^{42}$, desde que eles tenham as devidas adaptações à realidade da América Latina. Nessas sociedades, é difícil aceitar a tese de redução do Estado, já que ele é seu centro irradiador e é ele quem decide a política fiscal, monetária e científica. Além disso, garante o funcionamento da infra-estrutura necessária ao desenvolvimento do capital. Se os funcionários da Cipla conseguiram se organizar a ponto de não mais precisar da administração do antigo proprietário, eles não conseguiram se desvincular das burocracias do sistema. Tanto é que ao invés de negarem a participação do Estado na administração da empresa, exigem que ele se coloque na situação. ${ }^{43}$ Ao relacionar já na abertura da matéria a tomada da fábrica com o início do mandato Lula no Brasil, o programa exige uma posição do governo e do partido que se diz mobilizado pela causa dos trabalhadores (PT). Atitude essa tomada também pelo governo de Hugo Chávez, que analisa o governo Lula como incipiente no projeto integrador da América Latina e o vê como um governo neoliberal. "O presidente do Brasil decidiu um caminho determinado, que se pode sintetizar como um modelo neoliberal com rosto humano". ${ }^{44}$

2.2 - Lançamento do livro Latinoamericana - Enciclopédia Contemporânea da América e do Caribe

Ahistória política e social nos últimos 50 anos daAmérica Latina foi resgatada em uma produção territorial. O sociólogo Emir Sader lançou em Brasília uma Enciclopédia Contemporânea da América Latina e do Caribe, uma referência para ver o mundo desde o sul. ${ }^{45}$

Em matéria veiculada em 4 de outubro de 2006, a obra Latinoamericana - Enciclopédia Contemporânea da América Latina é apresentada como uma interpretação autêntica do continente. Uma forma de conhecer a trajetória dos povos que falam português e espanhol e todos aqueles que aqui vivem. Na reportagem, o sociólogo brasileiro Emir Sader, um dos organizadores da obra, fala que o livro é um resgate da América Latina através de sua diversidade. Uma enciclopédia que fala sobre temas como energia, Estado, culinária, esportes, literatura, arte e gênero através da perspectiva do século XXI.

Durante a noite de autógrafos, em Brasília, Sader colocou que a importância da obra está no fato de ajudar a promover o projeto de conhecimento e de integração da região, historicamente submetida a interpretações estrangeiras. Um trabalho de dois anos de pesquisa que envolveu representantes da intelectualidade latino- 
americana como Álvaro Garcia Linera, Ana Esther Ceceña, Gerardo Caetano, Pablo Gentili, Theotonio dos Santos, entre outros, em um total de 120 autores, em sua maioria com formação em Sociologia e História.

Para a escritora Ivana Jinking, uma das organizadoras do livro, trata-se de uma publicação pioneira, plural e tematicamente variada. Produzida quando pela primeira vez, e de formas distintas, os países latino-americanos se comprometem com um processo de integração soberana.

Venezuela e Cuba firmaram a Aliança Bolivariana das Américas (Alba), à qual se juntou à Bolívia. A Venezuela aderiu ao Mercosul. A Bolívia, que durante 25 anos se submeteu de forma incondicional ás regras do Fundo Monetário Internacional (FMI), volta a trilhar o caminho da independência. Privilegia-se a aliança entre Brasil, Cuba, Venezuela, Argentina Bolívia, Uruguai; acentua-se o caráter político do Mercosul, e sua ampliação para os demais países sul-americanos pode redefinir o mapa político do Ocidente. Esta enciclopédia é publicada ainda no momento em que o Brasil toma verdadeiramente consciência de que é parte integrante e indissociável da América Latina. ${ }^{46}$

O Brasil é o país que possui maior número de pesquisadores envolvidos nesse projeto ${ }^{47}$, com um total de 43 escritores. São economistas, sociólogos, historiadores, professores universitários, antropólogos e jornalistas que ajudam a construir o pensamento cultural, histórico e político da América Latina sob o olhar, majoritariamente, brasileiro.Dessa forma, por mais que os ensaios e os verbetes tenham sido pautados por normas comuns baseadas na objetividade do estilo geral, fica difícil não selecionar e mostrar realidades que a esses pesquisadores é comum. Mas se ao ler a obra não há como não se remeter ao Brasil dos últimos 50 anos, a matéria referente a Enciclopédia veiculada no "Realidades" não faz essa associação direta. Durante a apresentação da vídeo reportagem, Libertad Velascos coloca que o livro é uma produção territorial e uma referência para a bibliografia latino- americana.

O que o "Realidades" dá enfoque é na fala da repórter ao citar que o primeiro lugar a ter uma edição espanhola da obra vai ser a Venezuela, em uma clara necessidade de inserir o país detentor de $51 \%$ das ações da TeleSUR e um dos líderes do projeto de integração do continente na reportagem.

2.3 Índice de desemprego brasileiro:

Se até o segundo turno das eleições brasileiras o país teve poucas inserções 
na programação da TeleSUR, em especial do programa "Realidades", com a proximidade do pleito, o país e o governo Lula ganham outro destaque. No dia 19 de outubro, o país teve duas matérias apresentadas referentes ao mercado de trabalho.

A primeira delas trouxe índices do Instituto Brasileiro de Geografia e Estatística - IBGE. Segundo os dados apresentados nesta reportagem, o Brasil tem 20,5 milhões de trabalhadores, de um total de 22,4 milhões de pessoas que fazem parte da População Economicamente Ativa - $\mathrm{PEA}^{48}$, números que correspondem a uma taxa de $10,7 \%$ de desempregados no país. Na introdução da matéria, a apresentadora alerta ao telespectador que esse é um dos mais baixos índices de desemprego registrados no Brasil, já que quando o governo Lula assumiu a presidência o índice estava em 13\%. "Só em 2005, 1,8 milhão de pessoas entraram para o mercado de trabalho formal de uma das maiores economias latino- americanas" ${ }^{49}$. O Ministério do Trabalho do Brasil afirma que só em 2005, houve um aumento de 5,83\% das vagas no mercado de trabalho formal. Esse é o segundo melhor resultado da pesquisa desde o ano de 1985. "São basicamente professores, médicos e enfermeiros, gente que vai trabalhar para melhorar a organização do poder público municipal", afirmou Paula Montagnes do Ministério do Trabalho, em entrevista ao "Realidades". Além dessas áreas, o setor de turismo e de restaurantes também ajudou a aumentar esses números. Para Antônio Ibarra, consultor do departamento Intersindical de Estatística entrevistado na reportagem, isso representa um avanço na política de distribuição de renda. "É bom ressaltar que o crescimento econômico por si só não retrata a realidade. É possível promover a igualdade de renda com um baixo crescimento. Isso é uma novidade na América Latina" ${ }^{50}$. A vídeo-reportagem dá espaço e notoriedade ao trabalho realizado pelo governo Lula nos últimos quatro anos no Brasil. A matéria não entra no mérito do governo ter cumprido ou não promessas de campanha, já que, antes de assumir a presidência, Lula prometia a geração de 10 milhões de vagas de trabalho durante seu mandato.

Em meio aos números apresentados na matéria, o baixo crescimento do Produto Interno Bruto só teve uma breve explicação na fala do dirigente do departamento Intersindical de Estatística, já que dados divulgados pelo IBGE apontam um crescimento anual da economia brasileira menor do que o esperado. Em 2005, o Produto Interno Bruto cresceu 2,3\%, indicando uma desaceleração em relação ao ano de 2004, quando a economia do país registrou expansão de 4,9\%. ${ }^{51}$

Pelos dados da Comissão Econômica para a América Latina (Cepal) o crescimento brasileiro destoa dos 9,1\% registrados pela Argentina, 9\% na Venezuela e 3\% no México em 2005. O baixo crescimento se explica pelas medidas econômicas adotadas, como o pagamento da dívida pública, do controle da inflação 
e da restrição de investimentos governamentais em setores de infra-estrutura. Além da valorização do real que fez diminuir o desempenho das atividades exportadoras. Ao explorar apenas o aumento nos postos de trabalho, a matéria vem a defender o governo Lula. Tanto é que Antonio Ibarra chega a declarar que hoje promover a distribuição de renda não significa, necessariamente, crescimento econômico.

2.4 Participação da mulher no mercado de trabalho

Se crescem o número de trabalhadores formais no Brasil, as brasileiras lutam para entrar no mundo do trabalho em iguais condições. Uma realidade que não se repete só neste país como em todo o mundo ${ }^{52}$.

Esse foi o gancho adotado por Libertad para dar prosseguimento ao programa do dia 19 de outubro com matéria sobre a participação feminina no mercado de trabalho. Se a reportagem sobre a redução da taxa de desemprego mostrava um futuro promissor, a das condições de trabalho das mulheres previu ainda dias de incertezas e lutas, em uma conquista diária pela democracia.

Ao entrevistar embaixadoras de países como o Marrocos, citar dados mundiais e usar como referência lideranças feministas européias, a matéria sai do local, ou seja, dos índices do desemprego brasileiros, para discutir o global. Dessa forma, fica evidente que a reportagem prefere adotar uma posição de crítica não só a política de um determinado país, mas de todo um sistema. Em tom poético, Alexandre Ribondi, editor-chefe da sucursal da TeleSUR, abre a reportagem com uma fala da feminista francesa Simone de Beauvoir: "A mulher é o negro do homem". Em seguida, apresenta dados da Organização Internacional do Trabalho (OIT) que afirmam que as mulheres trabalham mais horas para receber salários menores e em postos de menor importância em todo o mundo. Para retratar os $35 \%$ de trabalhadoras latino-americanas, o repórter utiliza-se de dois exemplos, um caso de sucesso e outro de uma eterna batalha. A presidente dos laboratórios Sabin em Brasília, Janete Vaz, conta que começou seu trabalho em 1984, ainda durante a ditadura militar. "Sofremos muito e não foi fácil chegar onde chegamos". No início das suas atividades, o laboratório tinha apenas três funcionárias que se dividiam entre administrar, vender e cuidar da limpeza do espaço. Hoje, com mais de 22 anos de história, o empreendimento tem 459 funcionários. A matéria traz ainda a perspectiva da mulher africana, ao apresentar uma entrevista com Farida Jaidi, embaixadora do Marrocos no Brasil. Jaidi comenta que hoje as mulheres do norte africano representam cerca de $20 \%$ dos trabalhadores: "Hoje sem mulher não há acordos de trabalho e sem o respeito aos direitos das mulheres o país nunca poderá seguir adiante". O repórter, Alexandre Ribondi, finaliza a matéria dizendo que as mulheres entraram no século XX buscando seu lugar na sociedade, chegaram ao 
século XXI conscientes da sua força de trabalho, mas ainda têm um largo caminho a percorrer. As matérias sobre o desemprego brasileiro e a sobre vaga de trabalho para mulheres mostram assim que se nos últimos anos foi registrado aumento nos postos de trabalho no Brasil, essas vagas ainda não chegaram, necessariamente, às mulheres.

É interessante observar que a matéria, ao dividir os relatos entre mulheres de sucesso e outras que ainda lutam por seu espaço, acaba por legitimar, de uma forma ou de outra, o discurso do merecimento, aquele mesmo da Ética Protestante descrito por Max Weber. Dessa forma, se temos vitoriosas é por mérito delas e se outras ainda não chegaram a esse nível é porque ainda não batalharam o tanto que deviam. É de se perceber, também, um certo desengajamento brasileiro com o projeto integrador proposto pela TeleSUR. Os dados latino-americanos sobre a participação das mulheres no mercado de trabalho se limitam, em muitas ocasiões, ao exemplo brasileiro. Além disso, o repórter ao optar por abrir a matéria com um pensamento de uma feminista francesa, ainda mantém a interpretação européia no pensar e analisar o dia-a-dia latino americano.

\subsection{Mulheres na política}

Após a reeleição de Luiz Inácio Lula da Silva, o programa "Realidades" não deixou de discutir política brasileira. O programa do dia 2 de novembro trouxe dados sobre o perfil dos eleitores brasileiros e dos políticos eleitos. "Estão habilitados a votar no Brasil 125,9 milhões de pessoas, sendo que desse total $51 \%$ são mulheres. Entretanto, só $8 \%$ das vagas na Câmara de Deputados estão destinadas a elas. Serão nove senadoras e 42 deputadas, o que representa menos de $10 \%$ dos cargos eletivos". ${ }^{53}$ A reportagem fez parte de uma série produzida pela sucursal de Brasília que tinha como tema principal a mulher. O repórter que assina a matéria, Alexandre Ribondi, coloca que a participação da mulher na política faz parte de uma luta histórica ${ }^{54}$, que em 1998 conseguiu aprovar no Congresso a cota mínima de $20 \%$ de candidaturas femininas por partido político. Cota essa aumentada anos depois para $30 \%$. Além das políticas públicas voltadas à mulher, Mariani Libradoni (diretora da ONG feminista Agende), entrevistada na matéria, coloca que se faz necessário que os próprios partidos políticos assumam as candidaturas femininas e incentivem o financiamento de suas campanhas. Para a deputada reeleita Iriny Lopes (PT), ainda existem outros problemas. A falta de companheirismo e de solidariedade nas tarefas domésticas tem dificultado a participação efetiva das mulheres na política. A analista panamenha Mireya Suárez colocou que as lutas pela igualdade entre homens e mulheres pode ser o começo de mudanças estruturais na sociedade. "A partir do momento em que homens e mulheres são iguais, porque negros e brancos não vão ser?". ${ }^{55}$ A reportagem ainda 
coloca que a baixa participação feminina na política faz parte de uma crise de representatividade. As mulheres podem decidir uma eleição, já que é a maioria dos eleitores no Brasil, mas não conseguem transformar esses números em uma real e efetiva participação política. Tendem ainda a votar em homens e têm dificuldade em discutir temas importantes, como a questão do aborto.

Ao colocar a necessidade da participação feminina na política, a matéria cobra também mudanças estruturais na sociedade que precisam passar, necessariamente, por alterações no Estado. Um discurso que vem a legitimar os desejos do governo Lula que espera votar a Reforma Política a partir de 2007.

\section{Considerações finais}

Por se tratar de uma multiestatal, a TeleSUR sofre influência direta das eleições que acontecem na América Latina, especialmente quando essas se dão em seus países membros. Isso não quer dizer que o canal esteja associado tão somente aos chefes de estado de seus países. Mais do que isso, a TeleSUR Tv está ligada aos projetos de governo e de como os presidentes associados entendem a América Latina.

Dentro desse contexto, o Brasil do segundo mandato do governo Lula parece ter como prioridades projetos que foram muito pouco debatidos nos anos de 2002 a 2006, como o de integração da América Latina. O Lula que foi reeleito em 2006 com 58 milhões de votos parece estar mesmo diferente, tanto é que sua primeira viagem oficial como presidente reeleito foi feita à Venezuela em 12 de novembro. O motivo aparente da viagem era a inauguração de uma ponte sobre o rio Orinoco, construída através de financiamento do BNDES em parceria com a construtora brasileira Odebrecht, que ligará o estado do Amazonas e de Roraima a portos venezuelanos no mar do Caribe.

Para Edgardo Lander, professor de Sociologia da Universidade Central da Venezuela, a visita de Lula é uma expressão de apoio político a Chávez. Analistas internacionais consideram também a viagem como uma forma de agradecimento de Lula ao apoio dado pelo presidente venezuelano, principalmente durante o segundo turno das eleições brasileiras. Durante a campanha eleitoral no Brasil, órgãos de responsabilidade da Venezuela como a TeleSUR passaram a veicular matérias como a exibida pelo "Realidades", que afirmavam que foi no governo Lula que se registrou o índice mais baixo de desempregados no país, e reportagens veiculadas no site da multiestatal como a que dizia logo na manchete "Hay que frenar a la derecha y derrotar a Alckmim" $" 56$. Para o assessor de Assuntos Internacionais do governo brasileiro, Maximilien Arvelaiz, é muito importante que a Venezuela seja o primeiro país a ser visitado por Lula depois de sua triunfal vitória nas urnas. "Indica que a integração latino americana se aprofundará neste segundo mandato" $"$. 
O discurso de integração latino americana e a consolidação da TeleSUR TV fizeram com que os governos sul e centro americanos repensassem as políticas de concessão dos meios de comunicação na América Latina. Chávez ameaça não renovar o contrato de concessão da RCTV (um dos canais que fazem oposição ao seu governo) e Lula fala em uma Lei Geral das Comunicações de Massa e na criação de uma rede pública de televisão.

\section{BIBLIOGRAFIA}

BACCIN, C. A Televisão aberta na Argentina: uma distribuição desigual e uma programação metropolitana. In__ Televisão na América Latina. São Paulo:Metodista, 2000.

BOURDIEU, P. Sobre a Televisão. Rio de Janeiro:JZE, 1997.

CACCIMALI, M. C., SILVA, M. de F. J. Emprego e seguridade social: mais uma década perdida no mercado de trabalho da América Latina. In na-Encruzilhada da História Contemporânea. São Paulo, Xamã, 2003. . América Lati-

COGGIOLA, O.(org.) América Latina-Encruzilhada da História Contemporânea. São Paulo:Xamã, 2003.

COMPARATO, F. K. É possível democratizar a televisão?. In: inária: Televisão e Democracia. São Paulo: Companhia das Letras, 1991.

Rede Imag-

DEAECTO, M. e SECCO, L. A difusão dos livros marxistas na América Latina e no Brasil. In . América Latina-Encruzilhada da História Contemporânea. São Paulo, Xamã, 2003, cap. 3, p.69 a 80.

DUSSEL, E. Para uma ética da libertação latino-americana. São Paulo, Loyola, 1977.

LARANJEIRA, S. (Org.) Classes e movimentos sociais na América Latina, São Paulo, Hucitec, 1990.

MATTOS, L. Soy loco por ti. Folha de São Paulo, Folha Ilustrada, 24 de julho de 2005.

NOVAES, A. (Org.) Rede Imaginária: Televisão e Democracia. São Paulo: Companhia das Letras, 1991.

OURIQUES, N. (Org.) Raizes no libertador - Bolivarianismo e poder popular na Venezuela. Florianópolis:Insular, 2005.

PRADO, M. L. A formação das nações latino - americanas. São Paulo:Atual, 1994.

REIMÃO, S. (Org.) Televisão na América Latina. São Paulo: Metodista, 2000. 
REIMÃO, S. A televisão no Brasil - ontem e hoje. In . Televisão na América Latina. São Paulo: Metodista, 2000.

RICUPERO, B. Existe um pensamento marxista latino- americano?. In . América Latina-Encruzilhada da História Contemporânea. São Paulo, Xamã, 2003.

SADER, E., JINKINGS, I. (Orgs.) Latinoamericana - Enciclopédia Contemporânea da América Latina e do Caribe.São Paulo:Boitempo, 2006.

WEBER, Max. A ética protestante e o espírito do capitalismo. São Paulo: Martin Claret, 2005.

JÚNIOR, Antônio Reis. Em http://www.mnemocine.com.br/aruanda/tvtelejornalismo70s.htm acessado em 10/5/07 às 9h00.

http://www.historianet.com.br/conteudo/default.aspx?codigo=444 Acessado em 25/11. http://www.telesurtv.net/v3/secciones/concepto/index.php. Acessado em 25/10/06.

http://www.embarg.org.br/DisSM.htm 08/11/06 Acessado em 25/10 às 22h00.

ALADI,http://www.aladi.org/nsfaladi/prensa.nsf/fe2850c1a5e5052203256cef0 056d273/1f189dbb92fb036d03256ddd006b2df9?OpenDocument Acessado em 08/11/06 às $22 \mathrm{~h} 47$.

www.ca.ufsc.br/ela/terceiro/texto7.doc Em 08/11 2006.

http://educaterra.terra.com.br/voltaire/mundo/eua_monroe.htm. Em 8/11/06.

ZIBECHI, Raúl. http://www.telesurtv.net/v3/secciones/notasdeopinion/index. php?ckl=32 em 12/10/06 às $21 \mathrm{~h}$.

http://www.ibge.gov.br/home/estatistica/indicadores/trabalhoerendimento/pme/ pmemet2.shtm em 26/10/06.

http://www.telesurtv.net/v3/secciones/notasdeopinion/index.php?ckl=37 em 12/10/06.

http://www1.folha.uol.com.br/folha/bbc/ult272u58518.shtml em 11/11/06.

\section{NOTAS}

I Um dos pilares da TeleSUR Tv. Em http://www.telesurtv.net/v3/secciones/concepto/index.php , 25/I0 às $7 \mathrm{~h} 10$.

2 ○ conceito de América Latina utilizado neste trabalho é o proposto por Ivana Jinkings (2006, p.34) que afirma ser o subcontinente uma construção cultural, histórica e política, não apenas uma construção geográfica.

3 JINKINGS, 2006, p.34

4 MELLA Apud COGGIOLA, 2003, p. 304.

5 BORDIEU, 1997. 
6 No Brasil, a chegada da tv se confunde com a própria vida de Assis Chateuabriand. Ele foi o primeiro empresário nacional a importar aparelhos de tv e a montar a primeira emissora, a Tv Tupi. Foi só em 1962 que a rede Globo assinou um acordo com a empresa Time-Life que a transformou na maior empresa de comunicação do Brasil

7 A Tv Argentina nasce durante o governo de Juan D. Perón. Até 1960, o canal 7 era a única estação televisiva e tinha caráter público. Foi só a partir de um decreto do general Pedro Eugênio Aramburu que se começou articular a exploração individual das emissoras. Surgem assim, o canal 9 (com forte apoio financeiro da tv norte-americana NBC), canal I3 (com o apoio da rede estadunidense CBS) e canal I I ( com apoio da também norte-americana $\mathrm{ABC}$ ).

8 A Bolívia teve um contato relativamente tardio com o meio de comunicação: Tv. Foi só no governo de Luis Adolfo Siles Salinas em 1969 que se funda o canal 7 da Empresa Nacional de Televisão de caráter estatal e de serviço. A tv nasce assim, com a função de ser um difusor das idéias governamentais.Em 1973 começam a aparecer as primeiras tvs universitárias e só na década de 80 é que surgem as tvs privadas com apoio de indústrias eletrônicas de televisão da Espanha.

9 ○ início da televisão na Venezuela data de 1952, quando foi criado o primeiro canal de televisão nacional, o YUKA-TV. No ano seguinte, nasce a Televisa, canal 4, posteriormente adquirida pelo grupo Cisneiros e denominada atualmente Venevisión.

10 Time-Life é hoje uma marca registrada da Time Warner Inc.. Durante a década de 60, a empresa fez investiu milhares de dólares em tvs latino-americanas.

I I REIMÃO, 2000, p. 20.

I2 BOURDIEU, 1997.

13 Idem I I.

I4 BOURDIEU, 1997, p.28.

I 5 BOURDIEU, 1997, p.40.

16 BOURDIEU, 1997, p.76.

17 CUNHA, Rodrigo. Política Rege Concessões de Rádio e TV. Em http://www.comciencia.br/comcienci $\mathrm{a} /$ ? section $=8 \&$ edicao $=18 \& \mathrm{id}=189 \mathrm{dia} 10 / 05 / 07$ às $08 \mathrm{~h} 45$.

I 8 JÚNIOR, Antônio Reis. O percurso da televisão e do telejornalismo na década de 70. Em http://www. mnemocine.com.br/aruanda/tvtelejornalismo70s.htm acessado em 10/5/07 às 9h00.

19 SADER, 2006, p. 597.

20 Federação da Câmara de Lojistas da Venezuela.

21 Enciclopédia Contemporânea da América Latina, Apud, Bachelet, 2006, p. 314.

22 Anistiados em 1994, Chávez e vários militares passaram a pregar a necessidade de uma mudança constitucional no país, mostrando-se avessos á participação nos canais de representação política existentes. Tinham uma política básica: dissolver o Congresso e convocar uma Assembléia Constituinte. (SADER, 2006, p. 273)

23 RICUPERO, 2003, p.95.

24 "Além do golpe de 2002, a oposição organizou o paro petrolero, uma greve nacional, entre 2 de dezembro de 2002 a 3 de fevereiro de 2003. O terceiro ataque se deu nos marcos da Constituição bolivariana, com o mecanismo do referendo revogatório." Cf SADER, 2006, p. 274.

25 Cena mostrada no documentário A Revolução Não Será Televisionada, uma produção de Kim bartley e Donnacha $O$ 'Brian.

26 Petróleos de Venezuela S. A. A PDVSA possui, na Venezuela, seis refinarias com capacidade para processar I ,28 milhão de barris/ dia. (SADER, 2006, p.920)

27 TAVARES, Elaine. Ao povo, a comunicação. p. 103

28 COMPARATO, 1991, p. 301.

29 http://www.telesurtv.net/secciones/concepto/index.php em 10/5/07 às 23h.

30 http://www.telesurtv.net/secciones/concepto/index.php em 20/I I/06 às 2 I h05.

3I Aram Aharoniam, diretor geral do canal.

32 http://www.telesurtv.net/secciones/concepto/index.php em 20/I I/06 às 2 I h 12.

33 A TeleSUR é retransmitida diariamente pela Tv Floripa das $22 \mathrm{~h} 30$ às $13 \mathrm{~h} 30$. 


\section{8}

34 Eugênio Bucci (presidente da Radiobrás)

35 No caso brasileiro é nessa etapa que os textos em português são traduzidos para o espanhol.

$36 \bigcirc$ jornalista Alexandre Ribondi ocupou o cargo de editor-chefe da sucursal de Brasília até dezembro de 2006.

37 Quando Lula assumiu a presidência foi obrigado a assumir dívidas contraídas ainda no governo de Fernando Henrique Cardoso que comprometeram entre 3,9\% a 5\% do PIB brasileiro entre 2003 e 2005

38 Realidades é uma revista semanal veiculadas às quintas-feiras às I I h30 na TeleSUR TV.

39 No total das semanas pesquisadas seriam 12 programas Realidades, mas durante o Encontro dos Países não-alinhados que aconteceu em Cuba de I I a |4/9, o programa não foi veiculado. Nesse horário, a TeleSUR transmitiu ao vivo a chegada de Chávez a Cuba. Na edição de 6/I0, no horário do programa o canal transmitiu entrevista ao vivo com observadores internacionais.

40 http://www.telesurtv.net/secciones/concepto/mision/index.php em 9h/3 de 25//0/06.

4I Abertura da matéria lida em estúdio pela apresentadora Libertad Velascos em 17 de agosto de 2006.

42 No século XIX, Marx também proclamava a tomada de fábricas pela classe proletária. Para o pensador, o controle das máquinas levaria a uma outra forma de consciência e assim a classe estaria pronta para proclamar a Revolução. Nessa outra forma de governo, o Estado já não mais existiria e todos viveriam em comunhão.

43 LARANJEIRA, Sônia, 1990, p.22.

44 ZIBECHI, Raúl. http://www.telesurtv.net/v3/secciones/notasdeopinion/index.php?ckl=32 em $12 / 10 / 06$ às $21 \mathrm{~h}$.

45 Abertura da matéria veiculada em 04 de outubro no programa Realidades.

46 JINKINGS, 2006.

47 O segundo país em número de escritores da Enciclopédia é a Argentina com 19.

48 População Economicamente Ativa compreende o potencial de mão-de-obra com que pode contar o setor produtivo, isto é, a população ocupada e a população desocupada. Entende-se população ocupada como aquelas pessoas que, num determinado período de referência trabalharam ou tinham trabalho mas não trabalharam. A população desocupada efetiva é formada por aquelas pessoas que não tinham trabalho, num determinado período de referência, mas estavam dispostas a trabalhar e que para isso, tomaram alguma providência efetiva.

Em http://www.ibge.gov.br/home/estatistica/indicadores/trabalhoerendimento/pme/pmemet2.shtm à Ih08 de 26/10/06.

49 Chamada da matéria sobre o índice de desemprego brasileiro.

50 Antônio Ibarra, consultor do departamento Intersindical de Estatística entrevistado na reportagem.

5I LAGE, Janaína. Em http://www I folha.uol.com.br/folha/dinheiro/ult9 I u l 05546.shtml acessado no dia 22/10/06.

52 Chamada da matéria sobre a participação da mulher no mercado de trabalho veiculada em 19 de outubro no programa "Realidades".

53 Texto de Libertad Velascos que chama a matéria sobre a participação feminina na política em $02 / 11 / 06$.

$54 \bigcirc$ acordo de Beijing assinado pelo Brasil obrigava que os países signatários elaborassem políticas públicas voltadas a participação políticas das mulheres.

55 Mireya Suárez em entrevista ao "Realidades" de 02/I I/06.

56 Em http://www.telesurtv.net/v3/secciones/notasdeopinion/index.php?ckl=37 em I2// 0/06.

57 Em entrevista concedida pelo assessor à BBC Brasil, veiculada em http://wwwl folha.uol.com.br/folha/ bbc/ult272u585 I 8.shtml em I I/I I/06. 